\title{
Use of geospatial information and remote sensing data to support improved roadway access management
}

\author{
R. R. Souleyrette, P. E. Plazak \& D. J. Plazak \\ Center for Transportation Research and Education (CTRE), \\ Iowa State University, USA
}

\begin{abstract}
Urban and suburban roadways serve two distinct and sometimes conflicting purposes: providing mobility and allowing access to land and land developments. High-level urban roadways (e.g. arterials) should primarily serve mobility needs of travellers and goods. Low level, local roadways should primarily allow for land development access. Arterials that allow too much direct land access fail to function properly in terms of both traffic operations and safety. Such roadways are in need of access management. The operational and safety benefits of access management are impressive; access management has been shown to reduce crash rates on urban and suburban arterials by up to 40 to 50 percent. Identification of access management problem corridors (or corridors with excellent crash reduction potential) can be done in several ways. Physical features inconsistent with good access management practices can be identified. Alternatively, crash records can be used to identify outbreaks of crash types associated with poor access management. Ideally, both approaches may be used together. This paper will highlight four examples from the State of Iowa in the United States of the use of remote sensing imagery to extract access features and crash records to identify corridors with the most promise for improving safety through better access management. All four of these research studies are now being used by the Iowa Department of Transportation and/or metropolitan planning organizations in Iowa to improve the safety and operational performance of their urban arterials and other major roadways. Applications discussed in this paper include using remote sensing for estimating the level of access management, high priority commuting corridor identification the state of Iowa, regional access management planning for the Des Moines, Iowa USA metropolitan area, and the use of remote sensing for land use change detection and traffic monitoring. Keywords: access management, GIS, remote sensing, highway and road safety, land use.
\end{abstract}




\section{Introduction}

Roadways play two main roles: serving the mobility needs of motorists and providing direct access to land development, including for commercial businesses. Some types of roadways are functionally classified, designed, and regulated with the needs of high-speed through traffic in mind. A notable example of this type of roadway is the Interstate Highway System in the United States. These highways have no provision for direct land access. On the other hand, the vast majority of roadways in the world are local urban streets or local rural roads; they are planned and designed to provide little service to through traffic and essentially provide low-speed access to adjacent and nearby properties.

Access-related conflicts occur when the main role being played by a roadway becomes unclear. Most access-related conflicts tend to occur on routes that must provide a mixture of service to through traffic and access to property. Generally, these problem routes are functionally classified either as arterials or collectors. Access management involves careful planning and management of direct access from land development (both through the public roadway system or private driveways) to the arterial and collector roadway systems. This is done through a variety of treatments and standards, including driveway spacing standards, driveway corner clearance standards, alternative access routes such as frontage roads, and the installation of raised medians.

Access management projects are generally planned and implemented on a corridor-by-corridor basis [10]. However, more strategic approaches to access management are possible through the use of technologies such as geographic information systems (GIS) along with geospatial road inventory data, safety management data, land use planning information, and remote sensing data. This paper provides a number of illustrations of how geospatial data and remote sensing data have been used in the state of Iowa in the United States to improve the management of roadway access on a more regional, strategic basis.

\section{General benefits and impacts of access management}

Access management involves the careful planning and control of direct access to roadways intended to primarily serve through traffic. Access that needs to be managed includes direct access to land parcels via private driveways, intersections with minor public roadways, and breaks in raised medians. There is considerable research available on the practice, benefits, and impacts of access management [10]. The benefits of access management can be significant in terms of:

- Traffic safety. Crash rates decline by an average of 40 to 50 percent on well-managed arterial routes after access management projects are completed [1,6]. Personal injury crashes decline by about 25 percent on average. Crashes associated with motorists entering and leaving driveways (e.g. left turn, right turn, and rear end crashes) decline the most, as might be expected [1]. 
- Traffic operations. Access management projects also have a beneficial impact on traffic level of service, travel speed at peak hours, and congestion [10].

The impacts of access management on adjacent businesses are mixed. Managing access does not appear to negatively impact retail sales for the great majority of businesses along arterial corridors. However, when access is managed on a retrofit basis, a small percentage of automobile-oriented retail businesses (e.g. gasoline stations, fast food restaurants, and convenience stores) experience sales losses and customer complaints about difficulty in access. Overall, however, corridors with retrofit access management projects do not lag behind their communities in terms of business vitality and growth following completion $[3,5]$.

\section{Where is improved access management most critical?}

The importance of managing access on a route is mainly dependent on four factors - the amount of traffic (e.g. average daily traffic) the roadway carries, its functional classification, the surrounding land use, and the economic growth rate of the area surrounding a corridor.

Traffic volume is indicative of the throughput that the roadway must provide and thus the roadway's relative importance in the functional hierarchy of roadways. Direct access to adjacent properties creates "side friction" which impairs the ability of high-level roadways to efficiently serve through travel.

In terms of functional classification, access management is most critical on those roadways intended to serve long-distance, high-speed traffic. Typically, these are freeways (which are by definition totally access-managed), expressways, principal arterials, and minor arterials. When access is not properly managed on high-level roadways, their safety and operating performance suffers. In addition, when access is not well managed on high-level facilities, through traffic may divert to local streets. This causes additional safety, operational, and environmental problems and may give rise to demands by residents for "traffic calming" on local streets.

Access management is also more critical in certain land use districts. Commercial and industrial land uses generate many more trips per hour than other land uses, for instance residential development, parks, or agriculture. Thus, current and planned land use is a critical type of data for a strategic approach to access management.

A final factor that may generate future access management problems is the growth rate of the area surrounding a corridor. High rates of economic and demographic growth imply high growth rates in trip generation and traffic. If new direct accesses to arterials result, this may lead to safety and operational problems in the future. This in turn can greatly diminish the ability of an area's roadway system to serve traffic in a safe and efficient manner. 


\subsection{General strategic approaches to managing roadway access}

Three general approaches to using geospatial data and remote sensing are available to address access management on a regional strategic basis. These are to:

1) Focus on using remote sensing imagery and electronic inventories of roadway systems such that features and land use characteristics often associated with access management problems can be identified and analyzed

2) Use of highway crash records that have been located and which can be analyzed and mapped using GIS

3) Employ a hybrid approach and identify locations with high levels of change in traffic volumes.

While both the roadway inventory and crash record approaches are workable, the hybrid approach is superior since it can reveal both current and potential future problem locations. The following research projects for the state of Iowa in the United States are provided to illustrate these approaches.

\subsection{Use of remote sensing to identify access management elements for safety analysis}

The first of the illustrative studies provides an example of the "features inventory approach to the problem" [8]. The study investigated the potential of remote sensing techniques to reduce the cost of data collection required in access management programs, and enable systematic identification of priority areas for access management improvements. Safety prediction models incorporating access management may require data on driveway density and spacing, land use type, median and turn lane characteristics and intersection information. All of these data can be obtained from remotely sensed images of sufficient resolution. Two approaches were described: quantitative and qualitative. The quantitative approach calibrated a model incorporating access factors to predict crash rates. Explanatory variables related to access were counted and measured using field measurement and aerial photography, to determine the resolution of imagery required.

A $4.6 \mathrm{~km}$ corridor with a variety of access levels (e.g. varying driveway densities and median types) and land uses (commercial and residential) was selected for study. Digital orthophotography was available for the corridor at $15 \mathrm{~cm}, 0.60 \mathrm{~m}$ and $1.0 \mathrm{~m}$ resolutions. Parameters were calibrated for Sawalha's model using a technique suggested by Miller et al [7]:

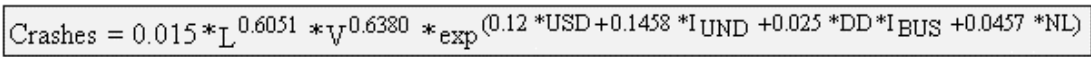

$\mathrm{L}=$ segment Length, kilometer

$\mathrm{V}=$ annual average daily traffic

USD $=$ un-signalized intersection density, intersections per kilometer

$\mathrm{DD}=$ driveway density, driveways per kilometer

\footnotetext{
$\mathrm{I}_{\mathrm{UND}}=$ indicator variable for undivided median treatment, 1 if undivided; 0 otherwise

$\mathrm{I}_{\mathrm{BUS}}=$ indicator variable for business land use, 1 if business; 0 otherwise

$\mathrm{NL}=$ between signal number of lanes.
} 
Results of the model (using field counts and measurements) were used to rank 17 corridor segments with regard to need for access management improvement. All access data required for the model could be obtained only from the $15 \mathrm{~cm}$ imagery, resulting in the same relative ranking of priority segments. Although data collection time aerial photos was reduced to less than one-half of the field data collection time, data extraction from imagery remains time consuming and expensive.

\begin{tabular}{|c|c|c|c|c|c|c|c|c|c|c|c|c|c|c|c|c|c|}
\hline & \multicolumn{17}{|c|}{ Segment Number } \\
\hline 60 & 1 & 2 & 3 & 4 & 5 & 6 & 7 & $\mathbf{s}$ & 9 & 10 & 11 & 12 & 13 & 14 & 15 & 16 & 17 \\
\hline 量 & & & & & & & b & & a & & $\begin{array}{l}\mathbf{e} \\
\mathbf{f} \\
\mathbf{h}\end{array}$ & $\begin{array}{l}\mathbf{a , c}, \mathbf{c} \\
\mathbf{c}, \mathbf{e} \\
\mathbf{c}, \mathbf{h} \\
\mathbf{M}\end{array}$ & $\begin{array}{l}\mathbf{a , c}, \\
\mathbf{d}, \mathbf{e} \\
\mathbf{r , h}, \mathbf{c} \\
\mathbf{M}\end{array}$ & $\begin{array}{l}\mathbf{a} \\
\mathbf{d} \\
\underline{\mathbf{g}} \\
\mathbf{M}\end{array}$ & & & \\
\hline 2 & & & & & & & he & $\begin{array}{l}\mathbf{a} \\
\mathrm{d} \\
\mathrm{e}, \mathrm{f}\end{array}$ & $\begin{array}{l}\text { b } \\
\text { c }\end{array}$ & & $\begin{array}{l}\text { a } \\
\text { d } \\
\text { C }\end{array}$ & g & $\underset{C}{\mathbf{b}}$ & $\begin{array}{l}\mathbf{c , e}, \mathbf{e} \\
\text { f,h } \\
\text { C }\end{array}$ & $\begin{array}{l}\mathbf{b}, \mathbf{d} \\
\mathbf{e ,}, \mathbf{r}\end{array}$ & $\begin{array}{l}\mathbf{d} \\
\mathbf{f}, \mathrm{g}\end{array}$ & $\begin{array}{l}\text { b } \\
\text { - }\end{array}$ \\
\hline 3 & & & & & $\mathbf{r}$ & $\begin{array}{l}\mathbf{a}, \mathbf{b} \\
\mathbf{c , d} \\
\mathbf{c}, \mathbf{d} \\
\mathbf{h}\end{array}$ & $\begin{array}{l}\mathbf{a}, \mathbf{c} \\
\mathbf{d , e} \\
\mathbf{f , g} \\
\mathbf{M}\end{array}$ & \begin{tabular}{|l|}
$\mathbf{b}$ \\
$\mathbf{c}$ \\
$\mathbf{h}$ \\
$\mathbf{C}$ \\
$\mathbf{M}$
\end{tabular} & $\begin{array}{l}\mathbf{h} \\
\mathbf{M}\end{array}$ & & $\begin{array}{l}\mathbf{b} \\
\mathbf{c} \\
\mathbf{g} \\
\mathbf{M}\end{array}$ & $\stackrel{\mathbf{b}}{\mathrm{C}}$ & $\underline{g}$ & b & $\begin{array}{l}\mathbf{a , c ,}, \mathbf{c ,} \\
\underline{\mathbf{g}, \mathbf{h}}\end{array}$ & a & $\begin{array}{l}\mathbf{d} \\
\mathbf{r} \\
\mathrm{g}\end{array}$ \\
\hline 4 & $\begin{array}{l}\mathbf{a , b} \\
\mathbf{c , \mathbf { b }} \\
\mathbf{M}\end{array}$ & & $\mathbf{M}$ & $\begin{array}{l}\mathbf{e} \\
\mathbf{r}\end{array}$ & $\begin{array}{l}\text { e } \\
\text { h }\end{array}$ & $\begin{array}{l}\stackrel{\mathrm{g}}{\mathbf{M}} \\
\mathbf{C}\end{array}$ & $\stackrel{\mathrm{g}}{\mathrm{C}}$ & $\underline{\underline{g}}$ & $\begin{array}{l}\mathbf{d} \\
\mathbf{f} \\
\mathrm{g} \\
\mathrm{C}\end{array}$ & $\begin{array}{l}\mathbf{b} \\
\mathbf{c} \\
\mathbf{d} \\
\end{array}$ & & & & & c & $\begin{array}{l}\mathbf{c} \\
\mathbf{h} \\
\mathbf{C} \\
\mathbf{M}\end{array}$ & $\begin{array}{l}\mathbf{a} \\
\mathbf{h} \\
\mathbf{C} \\
\mathbf{M}\end{array}$ \\
\hline 5 & $\begin{array}{l}\mathbf{e} \\
\mathbf{f} \\
\underline{\mathrm{g}} \\
\mathbf{1} \\
\mathrm{C}\end{array}$ & 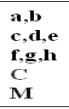 & 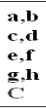 & $\begin{array}{l}\mathbf{a , b} \\
\mathbf{c , d} \mathbf{d} \\
\mathbf{h}, \mathbf{C} \\
\mathbf{M}\end{array}$ & $\begin{array}{l}\mathbf{a , b} \\
\mathbf{c , d}, \mathbf{d} \\
\underline{\mathbf{g}, \mathbf{C}} \\
\mathrm{MI}\end{array}$ & & & & & $\begin{array}{l}\mathbf{a , d} \\
\mathbf{f}, \mathbf{d} \\
\mathbf{a} \\
\mathbf{h} \\
\mathbf{M} \\
\mathbf{C}\end{array}$ & & & & & & b & c \\
\hline
\end{tabular}

Figure 1: Comparison of segment ratings by 3 methods.

The study also explored a more qualitative approach to need for access management using aerial photography. We investigated whether a quick, qualitative assessment of segment imagery could provide meaningful identification of priority corridors. To test this, training materials were prepared for test observers. Five categories of access management "quality" (where 1 is worst and 5 is best) were defined and explained to the observers with text and sample imagery. Eight observers were given brief training and asked to rate corridor segments. Quantitative model and actual, access-related crash history for each segment was also tabulated (crash rates were converted into 5 categories prior to tabulation of the qualitative assessments.) In most cases, the observer ratings compared favorably with model and actual ratings, as is indicated in Figure 1.

To summarize, remote sensing-based quantitative analysis of access management features can result in model results (segment ranks) which are essentially the same as those supported by field measurement. Use of remote sensing reduces the costs of data collection by 50 percent or more as opposed to field data collection on the ground. However, $15 \mathrm{~cm}$ or better resolution imagery is required to accurately identify and measure important access management roadway features such as driveways and median breaks.

In terms of the qualitative assessment, cost savings are even greater (for the test corridors, only 30 minutes were required to develop ratings as opposed to 
5 hours for the quantitative method, not including modeling time). However, some variability between observers exists, suggesting the need for further research and training.

\subsection{Iowa high priority commuting corridors}

This project was intended to produce a strategy for addressing current and future access management problems on state highway routes that serve as major routes for commuting into and out of major employment centers in Iowa [4]. These routes are mainly located outside urban areas. This study provides a good example of the crash records-driven approach to managing access. There were two basic goals for the research project:

1. To develop a ranking system for identifying high priority segments for access management treatments on primary highways outside metro and urban areas.

2. To focus on corridors that are the main commuting routes at present and that will be in the future.

The Iowa Department of Transportation (Iowa DOT) also wanted to be able to specifically focus on finding a limited number of four-lane corridors with at-grade intersections (Expressways) that ought to be given high priority for proactive attention to access management based on both current safety problems and future growth in traffic and development.

The research methodology consisted of two distinct activities. The first focused on finding corridors that exhibited signs of having access management problems at present. In Iowa, there are a limited number of routes where capacity and operations are issues. Therefore, this stage of the research focused entirely on safety and safety data rather than on highway inventory data (such as volumes).

The second major portion of the research involved the development of a statewide commuter traffic model. This was accomplished using ArcView and TRANPLAN. The model was constructed specifically for this project to provide estimates of future commuting traffic growth or decline on the 109 commuter routes being analyzed, and was simpler to construct than most statewide models as only relative traffic changes were needed (as opposed to robust absolute forecasts).

Four ranking indicators were compiled for all 109 corridor segments: 1) Access-related crash frequency ranged from a low of zero to a high of 529 over a three-year period with mean frequency of 60.2) Access-related crash rates ranged from zero (on a facility with no direct land access provided) to a high of 3.48 per million vehicle kilometers traveled, and the mean rate was 0.76 . See Figure 2 where the lightest colored corridor segments are the most problematic. 3) Access-related crash losses ranged from zero to a high of 36.7 million Euros, with a mean loss of just over 4.2 million Euros for a three-year time period. 4) The percentage of crashes deemed to be related to poor access management ranged from zero percent (on a freeway with complete access management) to a high of 33 percent with a mean value of 10.6 percent. The 109 corridor segments were located primarily outside of but adjacent to built-up urban areas. If similar 
calculations were conducted inside urban areas, it is very likely that the percentage of crash activity associated with access to land would be significantly higher.

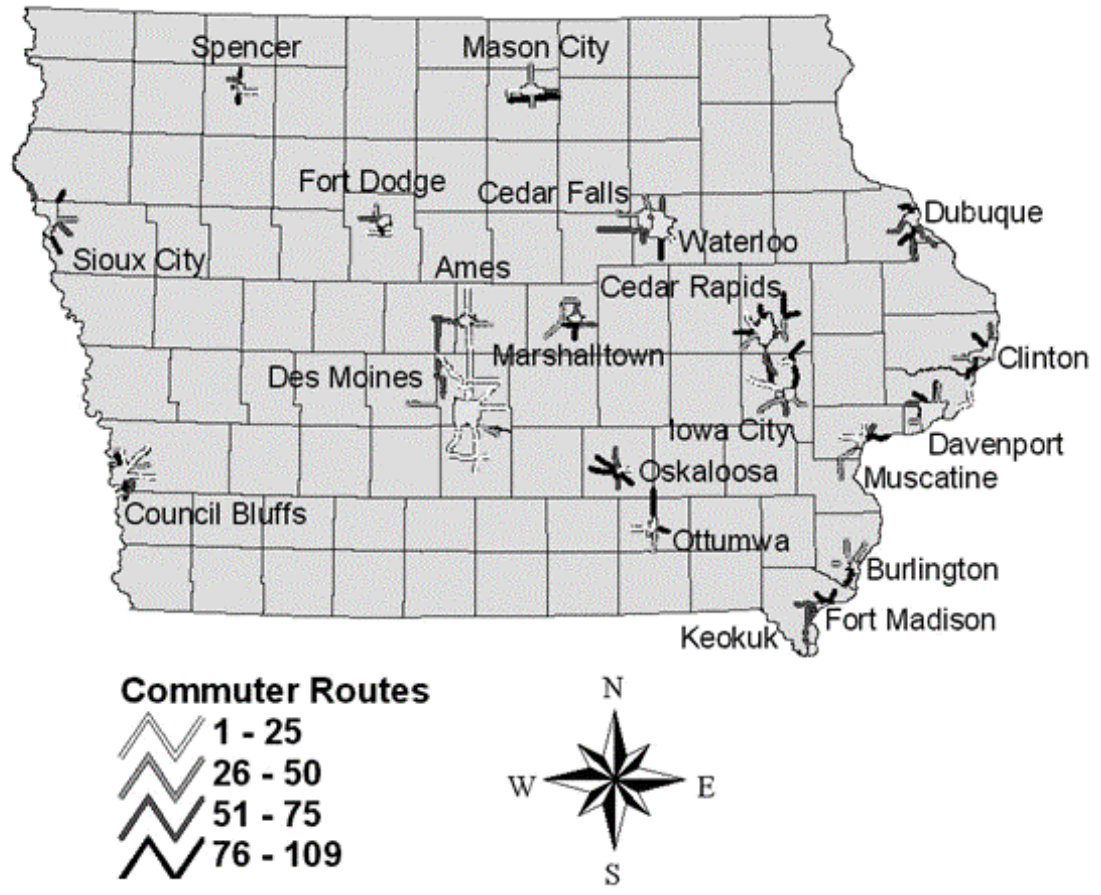

Figure 2: High priority corridors based upon access-related crash rates.

Results from the statewide model were used to identify those corridors expected to experience significant changes (positive or negative) in commuting travel in the next ten years.

Seven of the 109 corridor segments ranked in the top 25 on all four indicators (because frequency and loss are highly rank-correlated, both indicators were not used together in developing final composite priority rankings); another five corridors ranked in the top 25 on at least two indicators. Most of the highest ranked (most problematic) routes were on two-lane, rural highway crosssections, but a few were four-lane expressways with at-grade private driveways and public road intersections. In general, the Iowa DOT has practiced access management more thoroughly on its four-lane highways.

Most of the highly ranked corridors in terms of current safety problems were concentrated in two relatively small geographic areas of the state-near the Des Moines/Ames and Cedar Rapids/Iowa City metropolitan areas. These two areas are also the fastest growing areas of the state. This implies that there should be a high correlation between existing and future access management problem routes 
on the Iowa DOT's highway network. Many of these routes are going to be designated as priority routes for additional access management projects in the upcoming Iowa DOT long-range transportation plan.

\subsection{Des Moines Access Management Plan and Program}

The main purpose of the Des Moines Access Management Plan and Program project was to develop a systematic approach to access management in a medium-sized metropolitan area [2]. This research project provides a good illustration of the hybrid approach to access management problem identification discussed above.

Des Moines (with a metropolitan population of about 500,000 persons) is the largest such area located entirely within Iowa, but is a relatively small metropolitan area by international standards. To determine the most promising corridors in the Des Moines metropolitan area for access management treatments, access-related crash severity, access-related crash rates, and commercial driveway densities were calculated for 180 arterial roadway segments in the metro area. The top 20 highest commercial driveway densities, top 20 highest access-related crash rates, and top 20 access-related crash severities were identified from these calculations. The following material briefly describes the process for each step and the top 20 results. The analysis for the Des Moines Metropolitan area included all major arterial surface streets in the metropolitan area. This system was broken down into corridors. The corridors were further broken up primarily to identify specific locations that might be most promising for access management treatments. This resulted in a total of 180 analysis segments. The average segment length of the 180 segments was $3.2 \mathrm{~km}$ (two miles).

High commercial driveway densities are highly correlated with access-related crashes [6]. Common probable access-related crashes along urban arterials with a high density of driveways are rear-end, right-turn, and left-turn crashes. Driveway density indicates how many driveways per mile exist along each corridor. Commercial driveways have been found in past research to be critical, as commercial land uses generate more trips compared to residential driveways. As the driveway density increases along a corridor, more conflict points are produced and crash rates increase dramatically.

Commercial driveway densities were calculated for each corridor by taking the total commercial driveway count (per corridor) and dividing it by the total length of the corridor. This process utilized geographic information system (GIS) software, more specifically ESRI ArcGIS 8.3. Using $1 \mathrm{~m}$ resolution infrared orthophotos taken in 2002, driveway locations were identified manually along each corridor. An ArcGIS shapefile was created, using points to indicate all driveway locations along the entire arterial system for the metropolitan area. A current metropolitan land use coverage created by the Metropolitan Planning Organization (MPO) was then added to the GIS project to determine the driveways that provided access to commercial land use parcels. This was indicated in the GIS database for the total driveway inventory, thus allowing commercial driveways to be selected. Through ground-truthing of a sample of 
arterial segments using both windshield surveys and a ground level digital video log provided by the Iowa department of Transportation, it was determined that about 95 percent of driveway locations were correctly identified using the digital orthophotos. Errors tended to occur in areas with considerable shadowing or in areas with almost 100 percent pavement cover on the ground.

Crash rates per million vehicle miles traveled were figured for each study corridor. Crash rates were calculated using summed vehicle travel and crash frequencies for each corridor. ArcGIS was used to calculate crash rates for total crashes and probable access-related crashes. To identify the segments with the most promise for further analysis, the three rankings (crash rate, crash severity, and commercial driveway density) were summed for each corridor. This summed ranking served as the overall index ranking, which was then used to determine the top 20 high priority access management investigation segments in the Des Moines metropolitan area. Most of the top 20 segments are located in the older, core portions of the metropolitan area where a common development pattern involves small frontage commercial lots (generally only $18 \mathrm{~m}$ in width) along four-lane, undivided arterial roadways.

The result was the creation of a "most promising" list of arterial roadway segments in a metropolitan area for improved access management. (See Figure 3) This process is relatively simple and could potentially be replicated in other metropolitan areas that have similar geospatial data such as crash records, roadway inventories, and digital orthophotography. The researchers encountered few problems in gathering needed data and following the methodology outlined above; however, this certainly reflects the high quality of geospatial data that the researchers began with.

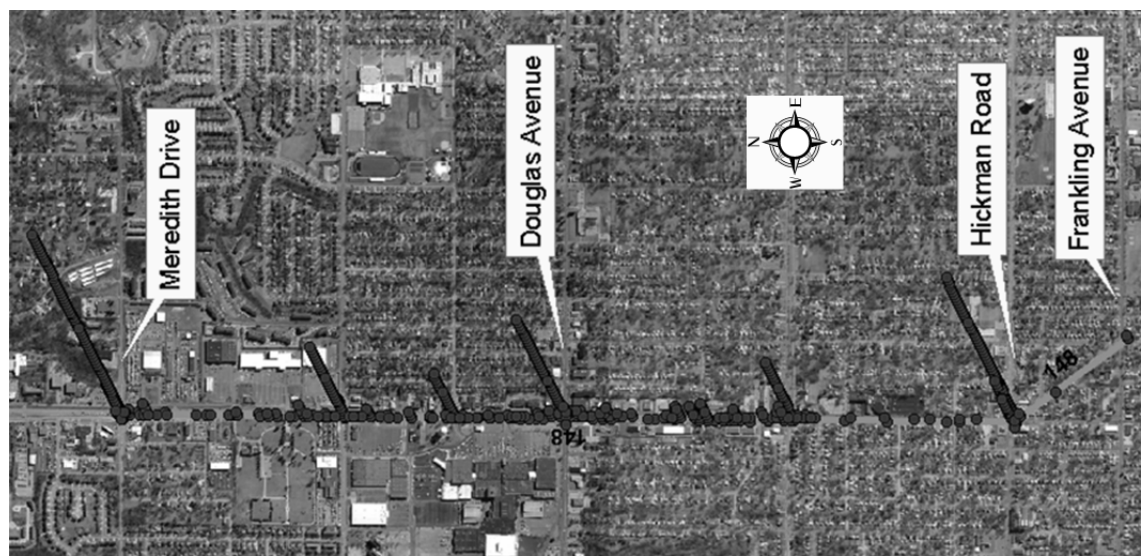

Figure 3: Crash map of the fifth most promising arterial segment for access management.

Being able to provide visual illustrations of access related crash problems to decision-makers proved to be a very beneficial outcome of this process. Each of these "most promising" segments must be further analyzed in terms of the types 
of access management issues present and the potential for treating them. Potential treatments to be examined may include driveway consolidation, addition of dedicated turn lanes, and the addition of two-way left-turn lanes or raised medians. For some of the corridor segments identified, potential solutions will be very limited due to a lack of available right-of-way. As part of another task of this research project, the Des Moines MPO will be developing the means to include access management improvement potential as a factor in its project programming process. The MPO will also incorporate access management considerations into its long-range planning process and educate decision makers about the value of access management.

\subsection{Remote sensing for traffic monitoring}

Highway agencies collect traffic count information at specified intervals for various purposes, among them, assessing the access needs of new development and the mobility needs of existing travel. In the absence of budgetary constraints, all road segments could be continuously monitored to determine traffic. As a practical matter, a subset of roads are monitored continuously to produce temporal characteristics of traffic flow, which in combination with limited duration sample counts of other road segments, are extrapolated to the entire road network.

Areas with rapid land development and therefore rapid change in traffic volumes are of particular interest for access management planning purposes. On the other hand, areas with static land use patterns (e.g., many rural areas well beyond the urban fringe) can be given less attention in planning for access management. Field tracking and reporting of land use change on a statewide basis is expensive and time consuming, and relying on reports from hundreds of local agencies may seriously lag the traffic monitoring process itself.

Temporal analysis of remote sensing imagery has the potential to identify land use change over large areas in a consistent and efficacious manner. Change detection, a common application in environmental analyses, can identify regions that have been transformed to built-up development during an analysis period, which can in turn be correlated to changes in traffic generation and distribution. Areas exhibiting little or no land use change over long periods are also identifiable via these methods.

The results could enable redirecting traffic count activities and related data management resources to areas that have experienced the greatest changes in land use and related traffic volume. Conversely, areas where land use changes are static or changes are statistically insignificant over time could be counted less frequently and/or with fewer counting devices.

In this research, two basic methods were developed and used to detect land use changes affecting traffic over a period of interest: 1) a "semi-automated" method that employed image classification and comparison, and 2) a "manual" visual inspection method for detecting built-up land use change supported by GIS technology [9]. The semi-automated method employed image-processing software to detect image differences and facilitate post classification comparison. The procedure evaluated radiance values from the image pixels and 
mathematically determined the differences between temporally different images of identical geographic extents. The process then converts identified raster change values to vector polygon change areas. Results were grouped to facilitate analysis of the areas with measurable and significant change.

Unfortunately, the semi-automated method tends to create large numbers of "false positive" land use change candidates. Those identified as false positives required intervention to eliminate them from further analysis. Evaluation of the time required to perform this post-processing data preparation, versus simply performing a manual inspection of the before and after imagery via visual comparison, suggested that the manual approach would be more reliable and equally as fast.

A custom visual basic application (VBA) was used to enable rapid navigation in ArcGIS, permitting a systematic review of the entire geographic expanse of the county at a consistent level of resolution and geographic extent.

Parcel acreage was computed and the type of land-use change activity was assigned to one of the four following categories:

- Rural development/agricultural uses - 75 trips per hectare.

- Low density residential - 125 trips per hectare.

- High density residential - 375 trips per hectare.

- Commercial and Industrial - 375 trips per hectare.

The area of land use change was calculated as well as the length of the intersected road segments by grid cell. The total number of daily trips for each land use polygon was then calculated using appropriate trip rates for the corresponding land use types. Daily travel for each road segment was calculated by multiplying the most recent traffic and corresponding road segment length. Using these values, the new daily trips and total daily local travel were determined for each grid cell.

The study suggested a strong correlation between trips predicted from remote sensing imagery and measured traffic patterns. However, this correlation could not be replicated where the temporal correspondence between image dates and traffic count data was poor. A more accurate application of the methods described in this study would therefore require that the timing of traffic cycle counts be coordinated with image acquisition dates. As imagery becomes more available and less costly over time, and is available in geographic extents which correspond to the traffic count cycles, such constraints would be minimized or eliminated. The analyses developed from this study suggest that there are large rural areas that could be physically counted less often than is the current practice. This would enable reducing the overall cost of the traffic monitoring program or potentially redirecting such resources to urban and suburban areas of the state where traffic volumes and mix are more volatile and demanding of more frequent on-the-ground monitoring.

\section{Overall summary and conclusions}

As the summaries of four research projects contained in this paper indicate, the application of geospatial data such as roadway inventory and crash record 
databases, geographic information systems, and remote sensing data provides for the opportunity to address roadway access management on a strategic, region wide basis rather than on a traditional corridor-by-corridor basis. Such region wide analyses allow decision-makers to determine the corridors in which access management investments are most likely to be needed for safety and operational reasons and to invest limited resources in a way that produces a larger return on investment.

High quality data, whether reliable and well-located crash data, detailed roadway feature inventories, or high resolution remote sensing data are needed in order to carry out such analyses.

\section{References}

[1] Maze, Tom and David Plazak, Access Management Awareness Program Phase II Report, Iowa Department of Transportation and Iowa Highway Research Board Report TR-402, Iowa State University Center for Transportation Research and Education, Ames, Iowa, December 1997.

[2] Plazak, David, Adam Garms, and Jon Rees, "Access Management Plan and Program for the Des Moines Metropolitan Area", Proceedings of the 2005 Mid-Continent Transportation Research Symposium, Iowa State University Center for Transportation Research and Education, Ames, Iowa, August 18-19, 2005.

[3] Plazak, David and Howard Preston, "Long-Term Impacts of Access Management on Business and Land Development along Minnesota Interstate 394", Proceedings of the 2005 Mid-Continent Transportation Research Symposium, Iowa State University Center for Transportation Research and Education, Ames, Iowa, August 18-19, 2005.

[4] Plazak, David and Reginald Souleyrette, "Process to Identify High Priority Corridors for Access Management Near Large Urban Areas in Iowa Using Spatial Data”, Proceedings of the 2005 Mid-Continent Transportation Research Symposium, Iowa State University Center for Transportation Research and Education, Ames, Iowa, August 21-23, 2003.

[5] Plazak, David, Paul Chao, Pola Gupta, Tom Sanchez, and Ken Stone, "The Impact Of Access Management On Business Vitality", Third National Access Management Conference, Committee on Access Management, Transportation Research Board; and Office of Technology Applications, Federal Highway Administration, Fort Lauderdale, Florida, October 4-7, 1998.

[6] Preston, Howard, Randy Newton, Deanna Keltner, and Chris Albrecht, Statistical Relationship Between Vehicular Crashes And Highway Access, Minnesota Local Roads Research Board Final Report MN/RC-1998-27, Minnesota department of Transportation, St. Paul, Minnesota, August 1998.

[7] Sawalha, Ziad, Tarek Sayed, and Mavis Johnson, "Factors Affecting the Safety of Urban Arterials", Proceedings of the Transportation Research 
Board 79th Annual Meeting (CD-ROM), Transportation Research Board, Washington, D.C., January 9-13, 2000.

[8] Souleyrette, Reginald, Srinivasa Veeramallu, and Shauna Hallmark, Use of Remote Sensing to Identify Access Elements for Safety Analysis, CTRE, ISU May 2001.

[9] Souleyrette, Reginald, Shauna Hallmark, Mark DeLong, and Zachary Hans, Remote Sensing Change Analysis Methodology to Support Traffic Monitoring Programs: Phase 2, CTRE Report 03-147, Iowa State University Center for Transportation Research and Education, Ames, Iowa, June 2004.

[10] Transportation Research Board, Access Management Manual, National Academies of Science, Washington, D.C., 2003. 